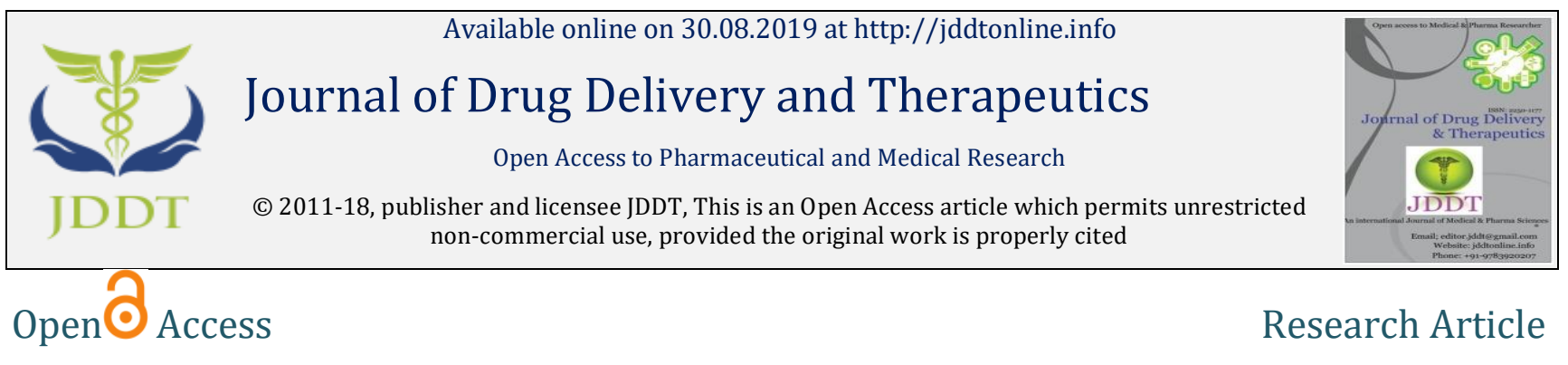

\title{
Comparative in vivo study of pure drug and fast dissolving tablets of Simvastatin
}

\author{
M. Suresh Babu ${ }^{1 *}$ T. E. Gopalakrishna Murthy ${ }^{2}$ \\ ${ }^{1}$ Department of pharmaceutics, Acharya Nagarjuna University, Nagarjunanagar-522510. \\ 2 Department of pharmaceutics, Bapatla College Of Pharmacy , Bapatla-522101.
}

\begin{abstract}
The objective of this study was to investigate differences in the pharmacokinetic patterns between pure drug and an optimized formulation of fast dissolving tablets of Simvastatin. The formulations were administered to 2 groups of white New Zealand rabbits (n=6) following cross over design pattern and the plasma levels were measured using LC-MS/MS method. Pharmacokinetic parameters were determined for each formulation. The comparison of the plasma time curves of the dosage forms showed that each dosage form caused significant differences in the drug plasma levels. The highest mean $\mathrm{C}_{\max }$ value was observed for optimized fast dissolving tablets (68.33 $\left.\pm 0.42 \mathrm{ng} / \mathrm{ml}\right)$ compared to pure drug $(27.72 \pm 0.31 \mathrm{ng} / \mathrm{ml})$. The mean time taken to peak plasma concentration for (Tmax) following administration of pure drug was $11.53 \pm$ 0.011 hours, while it was $6.09 \pm 0.072$ hour following administration of selected optimized fast dissolving tablets.The elimination rate constant (Kel) for pure drug and optimized fast dissolving tablets were found to be $0.58 \pm 0.012 \mathrm{~h}^{-1}$ and $0.53 \pm 0.014 \mathrm{~h}^{-1}$ respectively. The absorption rate constant (Ka) for pure drug and optimized fast dissolving tablets were found to be $1.68 \pm 0.01 \mathrm{~h}^{-1}$ and $5.53 \pm 0.02 \mathrm{~h}^{-1}$ respectively. The $\mathrm{AUC}_{0}$ ${ }_{\alpha}$ values observed with optimized fast dissolving tablets686.1. $\pm 2.07 \mathrm{nghr} / \mathrm{ml}$ in compared to pure drug values $191 \pm 1.43 \mathrm{nghr} / \mathrm{ml}$. Thus, the results of pharmacokinetic studies indicated rapid and higher oral absorption of Simvastatin when administered as its fast dissolving tablets. Both Ka and AUC were markedly increased by fast dissolving tablets.
\end{abstract}

Keywords: LC-MS/MS, Simvastatin, fast dissolving, In-vivo studies, pharmacokinetic parameters.

Article Info: Received 07 July 2019; Review Completed 14 August 2019; Accepted 18 August 2019; Available online 30 Aug 2019

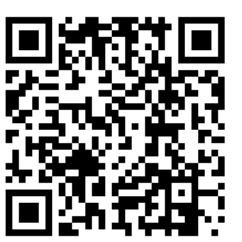

India

\section{Cite this article as:}

Babu M.S., Murthy T.E.G., Comparative in vivo study of pure drug and fast dissolving tablets of Simvastatin, Journal of Drug Delivery and Therapeutics. 2019; 9(4-A):490-496 http://dx.doi.org/10.22270/jddt.v9i4-A.3508

*Address for Correspondence:

M. Sureshbabu, Research scholar,Department of pharmaceutics, Acharya Nagarjuna University, Nagarjunanagar-522510,

\section{INTRODUCTION}

Simvastatin (SIM), a crystalline compound, is practically insoluble in water and hence poorly absorbed from the GI tract . It is a potent and specific inhibitor of 3-hydroxy-3methyl-glutaryl coenzyme A (HMG CoA) reductase, which catalyzes the reduction of HMG CoA to mevalonate. Thus, simvastatin arrests a key step for cholesterol biosynthesis in the liver and is widely used in the treatment of hypercholesterolemia and dyslipidemia as an adjunct to diet. After oral administration, simvastatin is metabolized to its $\beta$ dihydroxy acid form (simvastatin acid) by the cytochrome$3 \mathrm{~A}$ system in the liver, where it inhibits the rate-limiting step in cholesterol biosynthesis. This leads to up-regulation of low-density lipoprotein (LDL) receptors and an increase in catabolism of LDL cholesterol. Being a BCS Class II drug, it often shows dissolution rate-limited oral absorption and high variability in pharmacological effects. The major problem of Simvastatin is its very low water solubility, which results into poor dissolution rate. The pharmacokinetic performance of Simvastatin fast dissolving tablets was studied in a comparison with that of pure drug in rabbits ${ }^{4}$.

Materials and Methods: The in vivo study of the optimized formulations were performed as per the guidelines approved by the Committee for the Purpose of Control and Supervision of Experiments on Animals (CPCSEA), Ministry of social Justice and Empowerment, Government of India. Prior approval by Institutional animals ethics committee was obtained for conduction of experiments (Ref:VIPER /IAEC/I7/ 2017-2018, Dated 21-9-2017). Pure Simvastatin and optimized fast dissolving tablets were selected based on invitro release studies and stability conditions were chosen as dosage forms for administration.

Subject selection: The pharmacokinetic performance of Pure Simvastatin and optimized Simvastatin fast dissolving tablets were studied in a randomized crossover study design in rabbits. Twelve New Zealand healthy rabbits with a mean 
age of $10 \pm 2$ weeks and with a mean body weight of $3 \pm 0.2 \mathrm{~kg}$ were used in this study. Each group consisted of six rabbits $(n=6)$ each and were subjected for overnight fasting, it was taken care that there was no stress on the animals. Rabbits were randomly divided into two groups for different sampling time and each group was housed in one cage. Food and water were available ad libitum at all times during the experiment ${ }^{7-8}$. The study was conducted in a crossover design with 2 weeks washout periods in between the two experiments. The animal dose of Simvastatin was calculated relevant to human dose by using the following formula ${ }^{5-6}$. The above dosage form was administered through gastric intubation method.

Human dose of Simvastatin $=100 \mathrm{mg}$.

Animal dose $=\underline{\text { Human dose } \times \text { Animal weight }}$ Human weight

$$
=20 \times 3 / 70=0.85 \mathrm{mg}=1 \mathrm{mg}
$$

Blood sampling: About $1 \mathrm{ml}$ of blood samples were collected from the tracheal lobular vein of the rabbit using and the blood was stored in screw top heparinized plastic tubes, the sampling time for blood was done at 0 (before drug administration), $0.5,1.0,2.0,3.0,4.0$ and $6.0 \mathrm{hrs}$ after pure drug administration and at 0,1, 2, 4, 6, 8, 12, 16, 20, and 24 hrs after administration of Simvastatin fast dissolving tablets. The plasma was immediately separated by aspiration after centrifugation at $4000 \mathrm{rpm}$ for 5 minutes and frozen at $-20 \stackrel{\circ}{\circ}$ until analyzed by LC-MS/MS method7-8.

\section{Determination of Pharmacokinetic Parameters:}

Various pharmacokinetic parameters such as peak plasma concentration $\left(\mathrm{C}_{\max }\right)$, time at which peak occurred $\left(\mathrm{T}_{\max }\right)$, area under the curve (AUC), elimination rate constant $\left(\mathrm{K}_{\mathrm{el}}\right)$, biological half-life $\left(\mathrm{t}_{1} / 2\right)$ and mean residence time (MRT) were calculated using the noncompartmental pharmacokinetics data analysis software PK Solutions $2.0^{\mathrm{TM}}$ (Summit Research Services, Montrose, CO, USA) ${ }^{9}$.The pharmacokinetic parameters of the tested formulations were statistically analyzed using paired sample's t-test for normal distributed results of $\mathrm{C}_{\max }, \mathrm{K}_{\mathrm{a}}, \mathrm{K}_{\mathrm{e}}, \mathrm{MRT}$ and $\mathrm{AUC}_{0-\alpha}$ value. All tests were performed at 0.001 level of significance ${ }^{10}$.

\section{Estimation of Simvastatinin plasma (LC-MS/MS method 11 : Chromatographic conditions}

A summary of the chromatographic and mass spectrometric conditions is as follows:

UPLC

Mass spectrometer

Ion source

Polarity

Simvastatin

d3-Simvastatin

Column

Column oven temperature

Peltier temperature

Mobile phase

Flow rate

Volume of injection

Retention time

Run time

\section{Preparation of working standard solutions:}

\section{Preparation of Simvastatin standard stock solution:}

Simvastatin working standard equivalent to $5 \mathrm{mg}$ Simvastatin was accurately weighed and transferred into a 5 $\mathrm{ml}$ volumetric flask and dissolved in methanol. The solution was made up to the volume with methanol. The concentration of resulting solution was calculated by considering the purity of Simvastatin. The solutions were labeled and stored in a cold store at $2-8^{\circ} \mathrm{C}$.

\section{Preparation of internal standard stock solution:}

$0.005 \mathrm{~g}$ of $\mathrm{d} 3$-Simvastatinwas weighed accurately and transferred in to a $5 \mathrm{ml}$ volumetric flask and dissolved in methanol. The solution was made up to the volume with methanol. The concentration of resulting solution was calculated by considering the purity of Simvastatin $-\mathrm{d} 4$.

The solutions were labeled and stored in a cold store at 2$8^{\circ} \mathrm{C}$. Stock solution was diluted with $60 \%$ Acetonitrile in water solution to get a concentration of $75.00 \mu \mathrm{g} / \mathrm{ml}$. 


\section{Sureh Babu et al}

Calibration curve standards:

\section{Preparation of stock dilutions of standard Simvastatin solution:}

Stock solution of Simvastatin was diluted with $60 \%$ Acetonitrile in water solution to get a concentrations ranging from 1 to $140 \mu \mathrm{g} / \mathrm{ml}$.

\section{Spiking of plasma for calibration curve standards:}

Concentrations of Simvastatin ranging from 50 to 7000 $\mathrm{ng} / \mathrm{ml}$ were prepared with plasma and labeled them as CC1 to CC8. The calibration curve standards were prepared freshly for each validation run.

\section{Extraction procedure}

Step 1: Blank, calibration curve standards and the subject samples were withdrawn from the deep freezer and allowed them to thaw. The thawed samples were vortexed to ensure
Journal of Drug Delivery \&Therapeutics. 2019; 9(5):490-496

complete mixing of contents. To $0.25 \mathrm{ml}$ of plasma sample in a ria vial, $25 \mathrm{ul}$ of d3-Simvastatinstandard $(75 \mu \mathrm{g} / \mathrm{ml})$ was added. To plasma blank, 25 ul of $60 \%$ Acetonitrile in water solution was added and vortexed the samples to ensure complete mixing of contents.

Step 2: Add $2.5 \mathrm{ml}$ of tertitary butyl methyl ether, place on a shaker for 15 minutes and centrifuge for 10 minutes at $4000 \mathrm{rpm}$ at $20^{\circ} \mathrm{C}$. Transfer supernatant (organic layer) into the another rial vial. Evaporate this layer under a stream of nitrogen at $45^{\circ} \mathrm{C}$. The residue was reconstituted with $0.5 \mathrm{ml}$ of mobile phase and vortexed. The samples were transferred in to auto-injector vials and loaded the vials in to auto sampler. $10 \mathrm{ul}$ of sample was injected in to LC-MS/MS system. Analyte Concentrations of stock dilutions of standard Simvastatin solution with plasma were shown in Table 1.

Table 1:Analyte Concentrations of Stock Dilutions of Standard Simvastatin Solution with Plasma

\begin{tabular}{|c|c|c|c|c|c|c|c|}
\hline S.NO & $\begin{array}{c}\text { Sample } \\
\text { Name }\end{array}$ & $\begin{array}{c}\text { Analyte } \\
\text { Concentration } \\
\text { (ng/ml) }\end{array}$ & $\begin{array}{c}\text { Analyte } \\
\text { peak area }\end{array}$ & $\begin{array}{c}\text { IS Peak } \\
\text { Area }\end{array}$ & $\begin{array}{c}\text { Area } \\
\text { Ratio }\end{array}$ & $\begin{array}{c}\text { Calculated } \\
\text { Concentration } \\
\text { (ng/ml) }\end{array}$ & $\begin{array}{c}\text { Accuracy } \\
\text { (\%) }\end{array}$ \\
\hline 1 & $\begin{array}{c}\text { Plasma } \\
\text { Blank }\end{array}$ & 0 & 0 & 0 & 0 & N/A & N/A \\
\hline 2 & Blank+ISTD & 0 & 254 & 513643 & 0 & N/A & N/A \\
\hline 3 & CC1 & 50.05 & 3879 & 528938 & 0.01 & 50.407 & 100.71 \\
\hline 4 & CC2 & 100.15 & 6997 & 506198 & 0.01 & 97.939 & 97.79 \\
\hline 5 & CC3 & 250.300 & 17284 & 484351 & 0.04 & 258.119 & 103.12 \\
\hline 6 & CC4 & 500.650 & 34646 & 504084 & 0.07 & 500.215 & 99.91 \\
\hline 7 & CC5 & 1001.250 & 77371 & 577631 & 0.13 & 978.007 & 97.68 \\
\hline 8 & CC6 & 2002.500 & 134349 & 520675 & 0.26 & 1887.085 & 94.24 \\
\hline 9 & CC7 & 5006.250 & 345626 & 529110 & 0.65 & 4782.401 & 95.53 \\
\hline 10 & CC8 & 7008.750 & 578109 & 544120 & 1.06 & 7780.670 & 111.01 \\
\hline
\end{tabular}

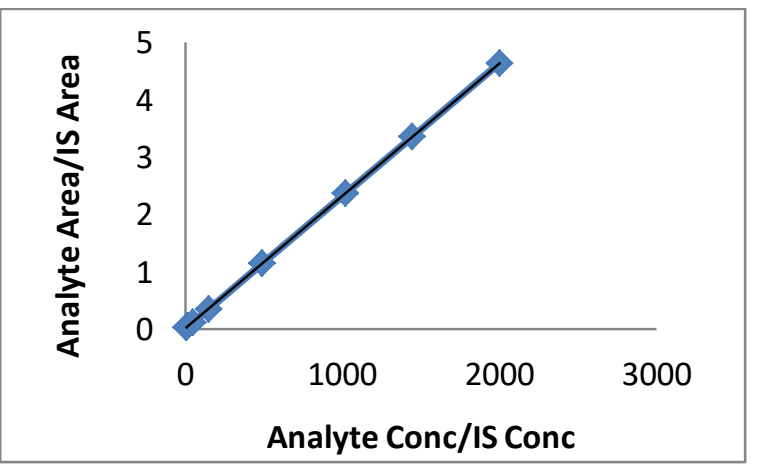

Figure 1: Calibration Curve for Estimation of Simvastatinin Plasma:

\section{Data processing}

The chromatograms were obtained by using the computerbased Analyst 1.4 .2 version software supplied by the Applied Biosystems, Canada. The concentrations of the unknown samples were calculated from the equation using regression analysis of spiked plasma calibration standard with $1 / x^{2}$ as weighting factor. $y=m x+c$; Where, $y=$ Ratio of Simvastatin peak area and ISTD peak area (analyte area / ISTD area); $\mathrm{x}=$ Concentration of Simvastatin ; $\mathrm{m}=$ Slope of the calibration curve; $c=y$-axis intercept value. Linear regression analysis equation of stock dilutions of standard Simvastatin solution with plasma is, $\mathrm{y}=0.000136 \mathrm{x}+$ 0.000454 . 


\section{Sureh Babu et al}

\section{RESULTS AND DISCUSSION:}

The in vivo experiments were conducted as per the protocol and procedure described earlier. Bioanalytical methods employed for the quantitative determination of drugs and their metabolites in biological matrix (plasma, urine, saliva, serum etc) play a significant role in evaluation and interpretation of pharmacokinetic data. For the successful conduct of pharmacokinetic study, the development of selective and sensitive bioanalytical methods plays an important role for the quantitative evaluation of drugs and their metabolites (analytes). The LC-MS/MS methods were
Journal of Drug Delivery \&Therapeutics. 2019; 9(5):490-496 highly sensitive and suitable for the detection of drug in plasma even in low concentrations. Calibration curves were constructed from blank sample (plasma sample processed without IS), blank+IS samples and eight point calibration standards for Simvastatin in plasma. Plasma concentrations of Simvastatin at different times were calculated and are shown in Table 2 and in Fig 2.Pharmacokinetic parameters such as absorption rate constant, elimination rate constant, half-life, AUC, and MRT were calculated from the plot of time versus plasma concentration and subjected to statistical analysis and the results were shown in Table 3.

Table 2: Plasma Concentrations of Simvastatin following oral administration of Pure Simvastatin and optimized fast dissolving tablets

\begin{tabular}{|c|c|c|}
\hline \multirow{2}{*}{$\begin{array}{c}\text { Time } \\
\text { (h) }\end{array}$} & \multicolumn{2}{|c|}{$\begin{array}{c}\text { Plasma concentration } \\
\text { (ng/m) (Mean } \pm \text { s.d) }\end{array}$} \\
\hline & Pure drug & Simvastatin \\
fast dissolving tablets \\
\hline 0 & 0 & 0 \\
\hline 0.5 & $08.51 \pm 1.86$ & $28.23 \pm 1.36$ \\
\hline 1 & $11.35 \pm 1.74$ & $36.44 \pm 1.78$ \\
\hline 1.5 & $12.51 \pm 1.52$ & $42.20 \pm 1.56$ \\
\hline 2 & $14.61 \pm 1.14$ & $45.24 \pm 1.24$ \\
\hline 3 & $16.75 \pm 1.64$ & $49.62 \pm 1.12$ \\
\hline 4 & $18.81 \pm 1.35$ & $54.12 \pm 1.65$ \\
\hline 5 & $19.62 \pm 1.43$ & $61.18 \pm 1.67$ \\
\hline 6 & $21.93 \pm 1.24$ & $68.33 \pm 1.85$ \\
\hline 8 & $22.76 \pm 1.43$ & $62.15 \pm 1.72$ \\
\hline 10 & $24.90 \pm 1.24$ & $57.42 \pm 1.22$ \\
\hline 12 & $27.72 \pm 1.27$ & $49.23 \pm 1.36$ \\
\hline 14 & $24.64 \pm 1.36$ & $42.20 \pm 1.43$ \\
\hline 16 & $21.96 \pm 1.53$ & $35.24 \pm 1.64$ \\
\hline 18 & $18.84 \pm 1.32$ & $28.53 \pm 1.18$ \\
\hline 20 & $15.92 \pm 1.21$ & $23.12 \pm 1.62$ \\
\hline 24 & $12.28 \pm 1.39$ & $17.18 \pm 1.47$ \\
\hline
\end{tabular}

FIGURE 2: Concentration-Time Curve of Simvastatin following oral administration of Pure Simvastatin and optimized fast dissolving tablets

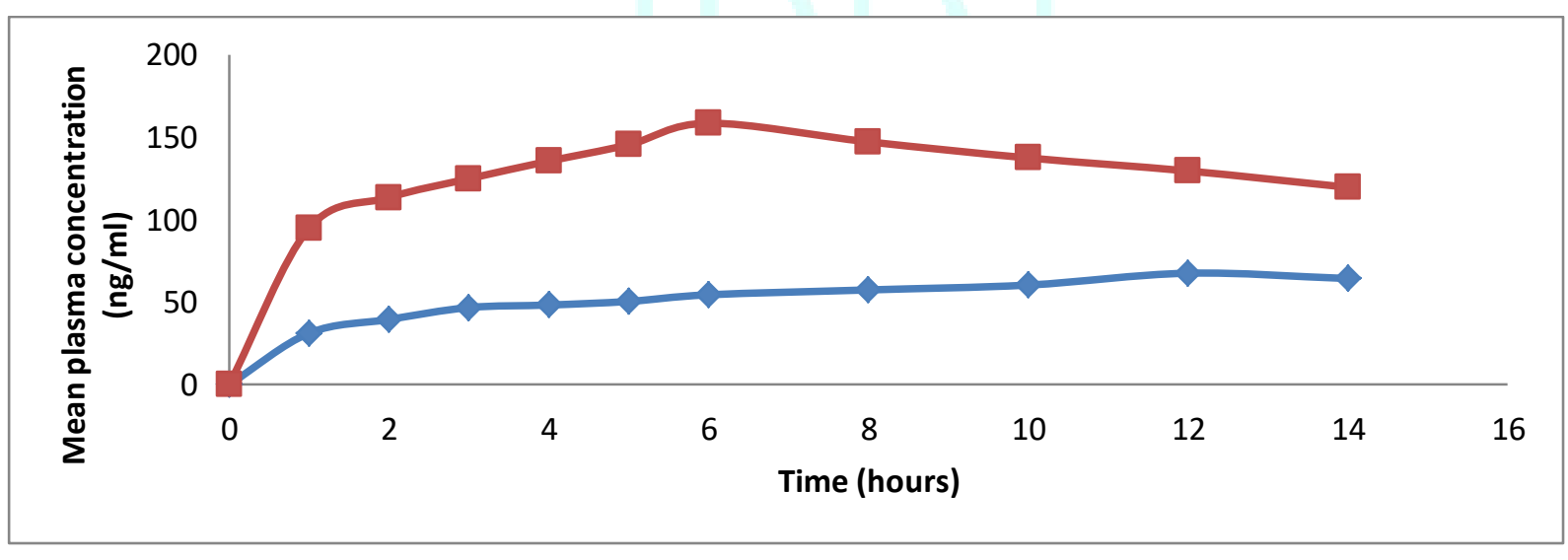

$(-\downarrow-)$ plasma Concentration -Time Curve of Simvastatin following pure drug administration

(-ø-)plasma Concentration- Time Curve of Simvastatin following optimized fast dissolving tablets administration 
Table 3: Statistical Treatment of Pharmacokinetic Parameters (Mean \pm S.D.) of following oral administration of Pure Simvastatin and optimized fast dissolving tablets

\begin{tabular}{|c|c|c|c|}
\hline Pharmacokinetic parameter & Pure Drug & $\begin{array}{l}\text { Optimized fast dissolving } \\
\text { tablets }\end{array}$ & Calculated value of ' $t$ ' \\
\hline $\mathrm{C}_{\max }(\mathrm{ng} / \mathrm{ml})$ & $27.72 \pm 0.31$ & $68.33 \pm 0.42$ & $26.70^{* * *}$ \\
\hline $\mathrm{t}_{1 / 2}(\mathrm{~h})$ & $11.53 \pm 0.011$ & $6.09 \pm 0.072$ & $40.75^{* * *}$ \\
\hline $\mathrm{K}_{\mathrm{el}}\left(\mathrm{h}^{-1}\right)$ & $0.58 \pm 0.012$ & $0.53 \pm 0.014$ & $6.87^{* * *}$ \\
\hline $\mathrm{K}_{\mathrm{a}}\left(\mathrm{h}^{-1}\right)$ & $1.68 \pm 0.01$ & $5.53 \pm 0.02$ & $19.67^{* * *}$ \\
\hline $\mathrm{AUC}_{0-\mathrm{g}}(\mathrm{ng} \mathrm{h} / \mathrm{ml})$ & $191 \pm 1.43$ & $686.1 . \pm 2.07$ & $256.60^{* * *}$ \\
\hline \multicolumn{4}{|c|}{$\begin{array}{l}\text { Null hypothesis (Ho):There is no significant difference between the pharmacokinetic parameters of Simvastatin obtained with } \\
\text { pure drug and optimized fast dissolving tablets. Table value of ' } t \text { ' with } 10 \mathrm{DF} \text { at the } 0.001 \text { level is } 4.587 \text {. }\end{array}$} \\
\hline \multicolumn{4}{|c|}{$\begin{array}{l}\text { Result: } H_{o} \text { is not accepted as the calculated ' } t \text { ' value more than the table Value of' } t \text { ' with } 10 \mathrm{DF} \text { at } 0.001 \text { levels of significance. It } \\
\text { was therefore concluded that there was significant difference between the pharmacokinetic parameters of obtained with pure } \\
\text { drug and optimized fast dissolving tablets. }\end{array}$} \\
\hline
\end{tabular}

The results indicated that the parameters significantly differed following optimized fast dissolving tablets administration, compared to pure drug administration. The highest mean $\mathrm{C}_{\max }$ value was observed for optimized fast dissolving tablets $(68.33 \pm 0.42 \mathrm{ng} / \mathrm{ml})$ compared to pure drug $(27.72 \pm 0.31 \mathrm{ng} / \mathrm{ml})$. The mean time taken to peak plasma concentration for (Tmax) following administration of pure drug was $11.53 \pm 0.011$ hours, while it was $6.09 \pm 0.072$ hour following administration of selected optimized fast dissolving tablets. The elimination rate constant (Kel) for pure drug and optimized fast dissolving tablets were found to be $0.58 \pm 0.012 \mathrm{~h}^{-1}$ and $0.53 \pm 0.014 \mathrm{~h}^{-1}$ respectively. The absorption rate constant (Ka) for pure drug and optimized fast dissolving tablets were found to be $1.68 \pm 0.01 \mathrm{~h}^{-1}$ and $5.53 \pm 0.02 \mathrm{~h}^{-1}$ respectively. The $\mathrm{AUC}_{0-\alpha \mathrm{V}}$ alues observed with optimized fast dissolving tablets686.1. $\pm 2.07 \mathrm{ng} \mathrm{hr} / \mathrm{ml}$ in compared to pure drug values $191 \pm 1.43 \mathrm{ng} \mathrm{hr} / \mathrm{ml}$. Thus, the results of pharmacokinetic studies indicated rapid and higher oral absorption of Simvastatin when administered as its fast dissolving tablets. Both Ka and AUC were markedly increased by fast dissolving tablets.

Figure 3: Chromatograms of reserve stock solution of Standard Simvastatin Solution with Plasma

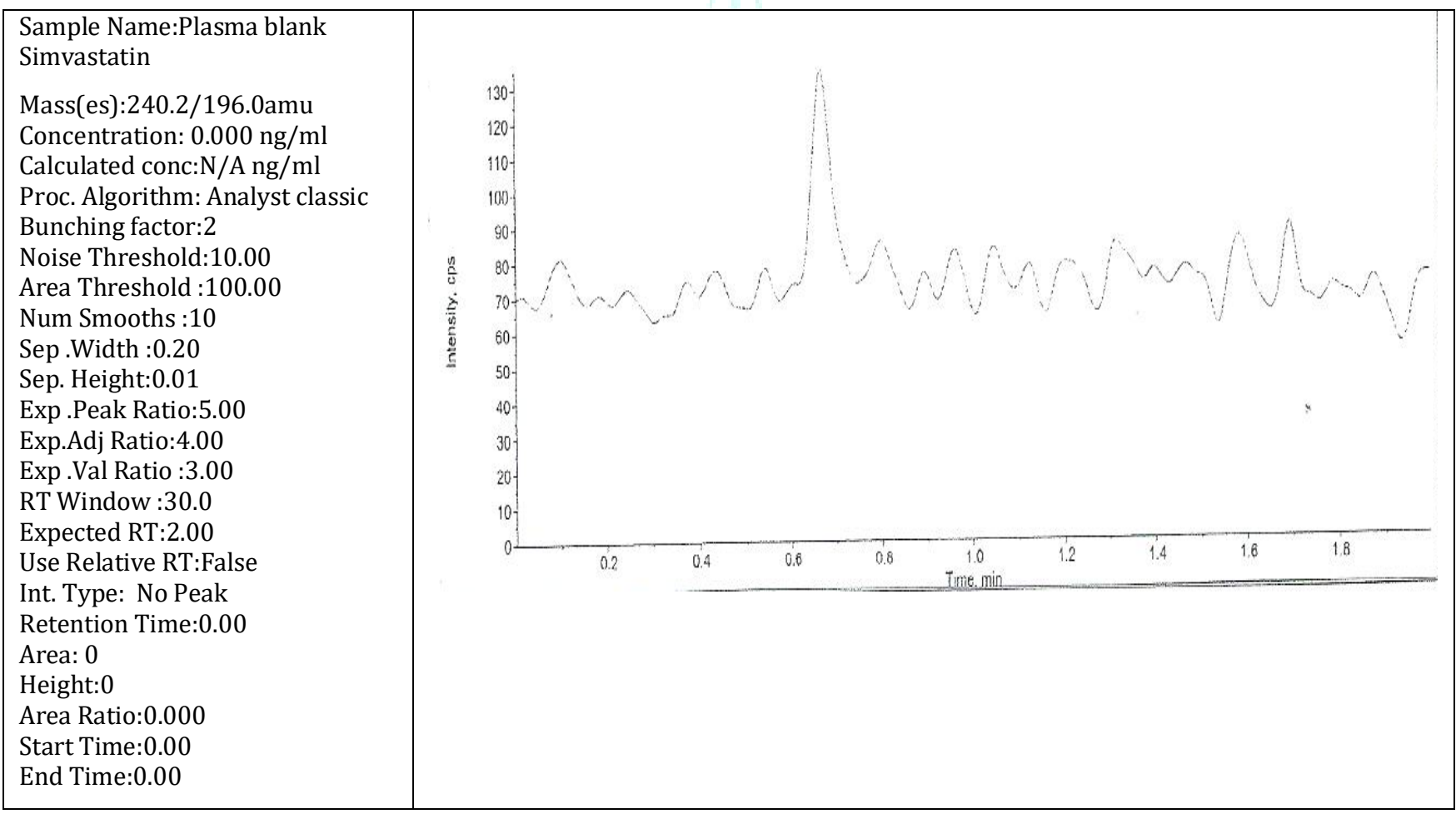


Sample Name: Plasma blankd3-Simvastatin

Mass(es):244.2/200.2amu

Concentration: $\mathrm{N} / \mathrm{A} \mathrm{ng} / \mathrm{ml}$

Calculated conc: N/A ng/ml

Proc.Algorithm: Analyst classic

Bunching factor: 1

Noise Threshold:20.00

Area Threshold :200.00

NumSmooths : 10

Sep.Width: 0.20

Sep. Height:0.01

Exp .Peak Ratio: 5.00

Exp.Adj Ratio: 4.00

Exp .Val Ratio :3.00

RT Window : 30.0

Expected RT: 1.80

Use Relative RT:False

Int. Type: Base To Base

Retention Time:1.85

Area:416

Height:125

Start Time:1.79

End Time:1.90

Figure 4: Chromatograms of Plasma blank and internal standard (d3-Simvastatin)

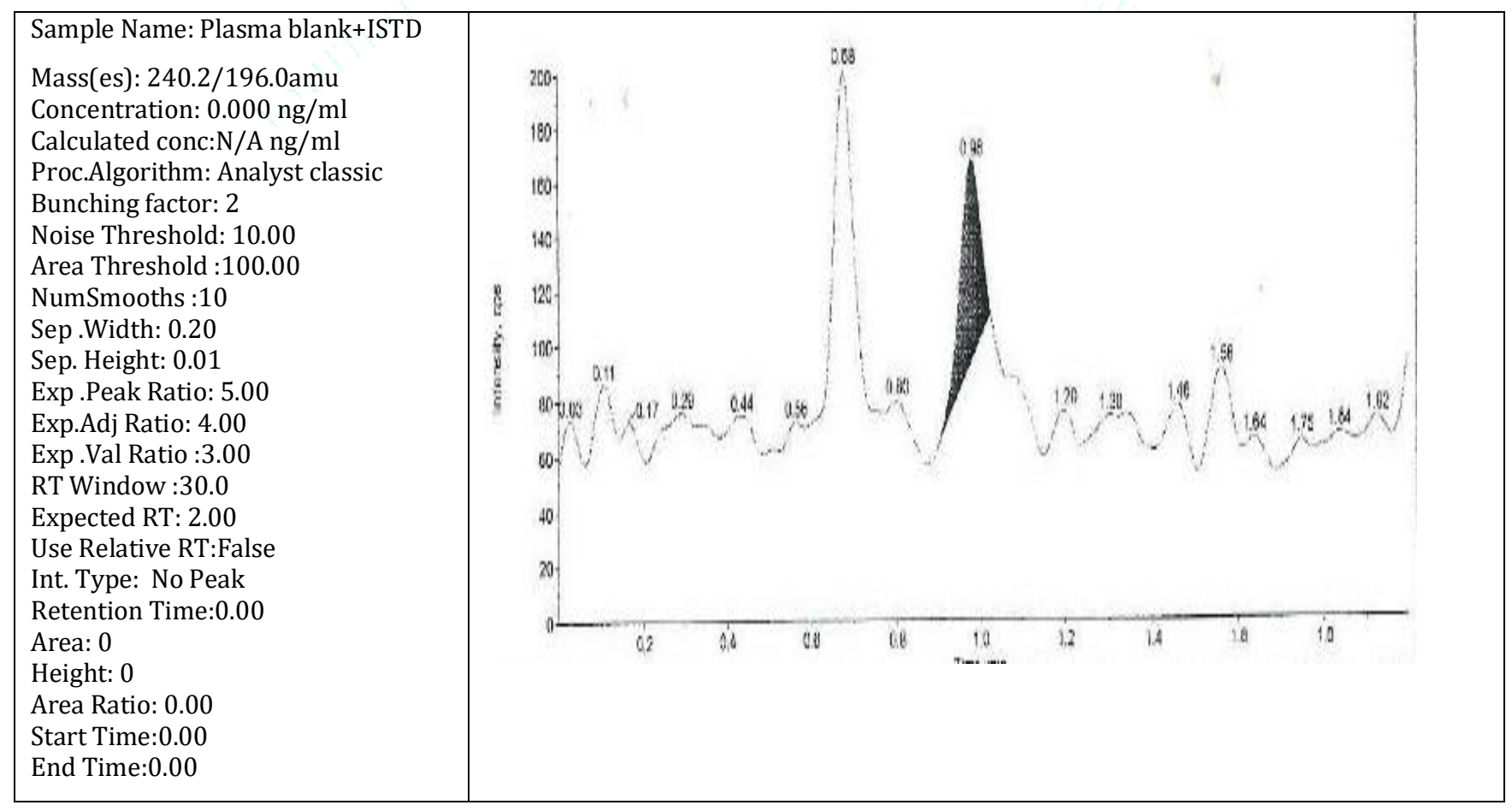


Sample Name: Plasma blank+ISTD -d3-Simvastatin

Mass(es): 244.2/200.2amu

Concentration: $1.000 \mathrm{ng} / \mathrm{ml}$ Calculated conc:N/A ng/ml Proc.Algorithm: Analyst classic

Bunching factor: 1

Noise Threshold:20.00

Area Threshold :200.00

NumSmooths : 10

Sep.Width:0.20

Sep. Height:0.01

Exp .Peak Ratio:5.00

Exp.Adj Ratio:4.00

Exp .Val Ratio $: 3.00$

RT Window :30.0

Expected RT :0.89

Use Relative RT:False

Int. Type: Base To Base

Retention Time:0.97

Area: 513643

Height: $1.3 e 5+0.005$

Start Time: 0.89

End Time: 1.03

\section{REFERENCES}

1. Indian Pharmacopoeia, Vol II, Govt. of India, Ministry of Health \& Family Welfare, New Delhi,The controller of Publications,2010; 147983.

2. Tripathi K D. NSAIDs .In, Tripathi $\mathrm{K}$ D(ed). Essentials of Pharmacology, 6th edition, New delhi, Jaypee Publication,;184-201

3. Guillaume F., Guyot-Hermann A.M., Guyot J.C., Spherical crystallization of meprobamate, Il Farmaco., 1993; 48: 73-485.

4. Nakamura H, Inoue T, Arakawa N, Shimizu Y, Yoshigae Y, Fujimori I, et al. Pharmacological and pharmacokinetic study of olmesartanmedoxomil in animal diabetic retinopathy models. Eur J Pharmacol 2005;512:239.

5. MahadeoMahadik, Sunil Dhaneshwar, RavindraBhavsar. A high performance liquid chromatography-tandem mass spectrometric method for the determination of Simvastatin in human plasma: application to pharmacokinetic study. Journal of biomedical chromatography. 2012; 26(10):1137-42.

6. Gopalakrishnamurthy $\mathrm{T}$ E,Mayuren $\mathrm{C}$. Pharmacokinetics of gliclazide alone and in combination with irbesartan in rabbits. Research. J. Pharm and Tech. 2008; 1(4): 418-421.
7. Zimmerman M., Ethical guidelines for investigations of experimental pain in conscious animals. Pain, 1983;16:109-110.

8. Winter CA, Risley EA and Nuss GW. Anti inflammatory and antipyretic activities of indomethacin. J PharmacolExp Ther.,1963; 141:369-376.

9.Pandey S, and GoyaniM,Formulation and evaluation of taste masked fast disintegrating tablets of Lisinopril.IntJofPharmTech Res 2010; 148:1639-43.

10. Sai Kishore V , Gopalakrishnamurthy T E,Mayuren C. Comparative In Vivo Evaluation of Diltiazem hydrochloride following Oral and Transdermal administration in Rabbits, Research J.Pharm. and Tech 2011; 4 (1):150-154..

11.MahadeoMahadik, Sunil Dhaneshwar, RavindraBhavsar. A high performance liquid chromatography-tandem mass spectrometric method for the determination of Simvastatin in human plasma: application to pharmacokinetic study. Journal of biomedical chromatography. 2012; 26(10):1137-42. 